\title{
Research on Pricing of Shanghai 50ETF Options Based on Fractal B-S Model and GARCH Model
}

\author{
Wanting Hu \\ School of Econmics, Jinan University, Guangzhou, China \\ Email: m18156795577@163.com
}

How to cite this paper: Hu, W. T. (2020) Research on Pricing of Shanghai 50ETF Options Based on Fractal B-S Model and GARCH Model. Modern Economy, 11, 407-425.

https://doi.org/10.4236/me.2020.112031

Received: December 20, 2019

Accepted: February 17, 2020

Published: February 20, 2020

Copyright $\odot 2020$ by author(s) and Scientific Research Publishing Inc. This work is licensed under the Creative Commons Attribution International License (CC BY 4.0).

http://creativecommons.org/licenses/by/4.0/

(c) (i) Open Access

\begin{abstract}
A reasonable option trading price will have certain guiding significance for option traders. Fractal B-S model and GARCH model are common pricing methods. This article explores which pricing method is more reasonable based on SSE 50ETF options. Due to the spikes and thick tails, conditional heteroscedasticity, and fractal characteristics of the SSE 50ETF option yield data, this paper performs stationary test, autocorrelation and partial autocorrelation test, $\mathrm{ARCH}$ test, and Hurst test on the daily sample rate series of the target sample. The characteristics of the yield sequence are used to construct a GARCH model and predict the daily rate of volatility. Finally, the volatility predicted by the GARCH model is used as the parameter value in the fractal Brownian motion option pricing method to realize the option pricing. At the same time, this paper calculates the pricing results of the BS option pricing method based on historical volatility, and compares the two options pricing results with the closing price of the option transaction price. The results show that the prediction of the Shanghai Securities 50ETF option pricing method based on the GARCH fractal Brownian motion model. The accuracy is significantly higher than the standard BS option pricing method.
\end{abstract}

\section{Keywords}

Fractal Brownian Motion, GARCH Model, SSE 50ETF Options, Volatility Prediction, Improved B-S European Option Pricing

\section{Introduction}

\subsection{Background and Significance of Topic Selection}

The full name of the SSE 50 ETF is the SSE 50 Trading Open-end Index Securities Investment Fund, which was established on December 30, 2014, and is the first ETF product in Mainland China. The SSE 50ETF is a completely passive 
index fund. It completely replicates the constituent stocks of the SSE 50 Index and the weight of each constituent stock. Its investment income comes from the SSE 50 Index. On February 9, 2015, the Shanghai Stock Exchange launched the Shanghai Securities 50ETF as the underlying trading option, namely the Shanghai Securities 50ETF option. The launch of this option has not only enriched China's financial derivative products, but also marked a key step in the development of the option derivative market in China; it has also achieved a joint development of the current market, improved the operating efficiency of the spot market, and further enhanced the ability to serve the real economy. Option pricing is one of the important contents of modern financial theory. Reasonably pricing options are the prerequisite for options to play their important role in the financial market. It has important practical significance for China to further develop derivatives, avoid risks, and stabilize financial markets. How to effectively establish the SSE 50ETF option pricing model is also an important topic.

Although the development of options in China started late, some scholars have conducted research on option pricing. Ji (2015) used the GARCH model and the B-S model to analyze the SSE 50ETF option price, and concluded that the GARCH model has a good fitting effect on small sample data. Liu et al. (2018) conducted European barrier option pricing research in a mixed-fraction Brownian motion environment, and derived the European barrier option call put-parity relationship, and then entered the knockout option relationship to introduce all types of barrier option pricing formulas. Cheng et al. (2018) considered the pricing of European options when paying continuous dividends under the sub-fractional Brownian motion environment, and estimated the parameters in the pricing model. The unbiasedness and strong convergence of the estimators were discussed. It can be seen that both the fractal Brownian motion model and the B-S model are common method models for studying option pricing methods. In this paper, the Shanghai 50ETF is the research object. Based on the comparison between the pricing of the two models and historical actual conditions, which model is selected as a more reasonable pricing model.

\subsection{Comparison between Traditional B-S Option Pricing Method and Fractal Brownian Motion Option Pricing Method}

The B-S option pricing method is proposed under the assumption that the underlying asset prices are independent of each other and follow the geometric Brownian motion, and that the return on the underlying asset is independent and identically distributed and follows the normal distribution. However, in recent years, a large number of scholars' research on the capital market has shown that the price of financial assets does not follow the geometric Brownian motion, that is, the rate of return of financial assets does not follow a normal distribution, but a distribution of peaks and thick tails. It is not independent, but there is long-term correlation. Therefore, the B-S option pricing method has some limitations in practical application. 
The fractal Brownian motion option pricing method is the first time that $\mathrm{Hu}$ $\mathrm{Y}$ applied it to financial option pricing based on Mandelbrot B's fractal Brownian motion. The main difference between fractal Brownian motion and geometric Brownian motion is that the increment in fractal Brownian motion is not independent, while the increment in geometric Brownian motion is independent. Because the fractal Brownian motion option pricing method can well characterize the self-similarity, thick tail, and long memory of the underlying asset price, and does not require the underlying asset prices to be independent of each other, obey the geometric Brownian motion, and the underlying asset return rate to follow a normal distribution Therefore, it is more in line with the actual characteristics of financial option prices. Subsequently, many researchers used the fractal Brownian motion option pricing method to study the pricing problem of the stock option market under the assumption that the stock price volatility was constant. It was verified that the fractal Brownian motion option pricing method was superior to B-S and other option pricing methods.

\section{Literature Review}

\subsection{Literature Review of Volatility Models at Home and Abroad}

There are many researches on the modeling and prediction methods of volatility. Robert Engle proposed an autoregressive conditional heteroscedasticity (ARCH) model in 1982 to build and predict conditional heteroscedasticity models. Early ARCH family models include ARCH-M models, TARCH and NARCH models. The ARCH-M model was first proposed by Engle, Robins, and Lilien in 1985. The ARCH model takes into account the variation of conditional variance over time to analyze volatility, and the analysis of volatility is inseparable from the risk. Engle et al. further took into consideration the important use of conditional variance as a risk measure that changes over time, linking risk and return, and proposed the ARCH-M model, which allows conditional heteroscedasticity to directly affect the mean of returns. The TARCH model considers the variance is affected by the sign of the disturbance term, and NARCH is an important nonlinear ARCH model. Both of them specifically address some of the defects of the linear ARCH model, which is more than the linear ARCH model advanced. However, in some cases, the ARCH model cannot express the information that the autocorrelation coefficient is slowly decaying, and in practice, the estimation of the completely free lag distribution often leads to the destruction of non-negative constraints. To solve the shortcomings of the ARCH model, Bollerslev (1986) proposed the GARCH model in 1986. The variance of the random disturbance term is not only related to the variance of the lagging disturbance term, but also to the lagging disturbance term itself. After that, the EGARCH (Exponential GARCH) model was proposed by Nelson in 1991. The biggest advantage of the model is that it takes the form of the logarithm of conditional variance, which allows the assumption of the sum of the squared residuals and the 
conditional variance to be more advanced. Flexible to capture asymmetric conditions (good news and bad news have asymmetric market volatility). China's financial derivatives industry started late, and there are few innovative studies on volatility using the GARCH family, and more emphasis is placed on applications. Representative examples are Zheng and Huang (2010). The comparison of the prediction capabilities of the GARCH model and the implied volatility is mainly based on the research on the volatility of the Hong Kong Hang Seng Index Options Market. There are more information and strong forecasting ability; but when forecasting for a long period of time, the implied volatility contains more information and strong forecasting ability. At the same time, the more active the options market transactions, the more comprehensive the information it reflects, and the stronger the ability to predict implied volatility. In addition, Huang and Zhong (2007) also evaluated the volatility prediction of GARCH models. The research results show that the GARCH model is used to comprehensively estimate the rate of return and out-of-sample prediction. The use of $\mathrm{M}-\mathrm{Z}$ regression and loss function shows that it performs very well and can perform better predictions.

The study of volatility can reflect the market's expectations of the degree of future volatility, thereby achieving the purpose of risk prevention and guiding transactions. For example, in 1993 the Chicago Board Options Exchange compiled the VIX Volatility Index based on the S \& P Index. To this day, the volatility index has become the main reference indicator for measuring investor psychology and market volatility. It uses stock index option prices to calculate expected short-term market volatility. The volatility index can not only quantify the price changes of derivatives and market risks, but also provides investment opportunities due to its volatile nature. The market can make full use of its characteristics to develop tradable volatility products for hedged trading and arbitrage trading.

Research on volatility can give investors a better understanding of risk. At present, domestic stock index options are only listed and traded on the Shanghai Stock Exchange 50ETF options. The study of volatility can lay the foundation for the subsequent listing of more financial options.

\subsection{Literature Review on Options Pricing at Home and Abroad}

Since 1970, on financial option pricing, Black-Scholes (BS) option pricing, HullWhite option pricing, binary tree option pricing, and fractal Brownian motion option pricing have emerged, among which BS option pricing and fractal Brown Exercise option pricing are more common and easy-to-use methods.

With the development of the foreign option market, the empirical research on option pricing has become more and more in-depth, mainly including the improvement of variables or parameters and the validation of models. The empirical start on the improvement of variables or parameters was the earliest. Levy and Byun (1987) tried to test the reliability of BS model pricing by deriving the 
implied volatility of the price based on the confidence interval of the estimated variance; Corrado and Su (1998) through empirical research on the S \& P 500 stock index options, it is found that the return volatility is negatively correlated with changes in the stock index level, and the parameters of the stochastic volatility option pricing model are estimated and predicted, and the practical application value of the stochastic volatility option pricing model is revealed. Saurabha and Tiwari (2007) in order to solve the volatility smile problem in the traditional BS option pricing model, two statistical variables of skewness and kurtosis are introduced. Based on the relevant data of S \& P 500 options, the volatility is used. Estimating the prices of deep currency options and deep out-of-the-money options can produce prediction results that are closer to the market price of options; Andrés-Sánchez (2017) analyzes the option pricing model based on the basic theory of the fuzzy BS model, through the actual trading of Spanish stock index options Price fitting related parameters, fuzzy BS model from different angles. The ability to predict the price of stock index options is evaluated. Regarding the validity analysis of the model, scholars' empirical evidence is based on different theoretical models. Bailey and Stulz (1989) performed dynamic analysis and empirical testing of stock index options based on stochastic interest rate option pricing models and stochastic volatility option pricing models, respectively; Yung and Zhang (2003) used S \& P 500 option data to model GARCH option pricing models Multi-angle empirical analysis with the pricing effect of the traditional BS model, and found that the GARCH model performs better than the traditional BS model in sample evaluation and sample prediction; Kim and Lee (2013) proposed an estimate of volatility without arbitrage Rate model, using KOSPI 200 index options to conduct empirical analysis of three indicators: intra-sample pricing, out-of-sample pricing and hedging error, verifying the effectiveness of the model in option pricing; Oliver and Li (2015) from the equilibrium interest rate and consumption Based on the perspective of capital asset pricing, based on the price data of European call options, a reasonable prediction of the price jump time in the jump-diffusion option pricing model is realized to clarify how the relevant parameters of the model affect the actual option pricing.

Domestic research on the options market started late. With the further opening of the financial market, the options trading market has become more and more active, and research on pricing models has become more common.

Early scholars' empirical research mainly focused on the pricing analysis of alternatives to domestic market options and the data simulation of foreign market-related options. Song et al. (2013) by studying the game between transferable bond trading terms, introducing game options and selecting domestic convertible bonds for empirical analysis, the double reflection wall backward stochastic pricing model has better price simulation and prediction effects; Liao et al. (2013) selected the Korean stock index option KOSPI200 as the research object, and used the fractional Brownian motion option pricing model to fit relevant actual data, and conducted an empirical test on the accuracy and effectiveness of 
the model. Qin et al. (2019) based on the fractional BS model, taking into account the uncertainty of the financial market including randomness and ambiguity, using stochastic analysis, fractal theory, and fuzzy set theory to construct a long memory characteristic of financial markets under uncertainty European option pricing model. Wang et al. (2019) combined a Heston model and a 3/2 model to establish a two-factor $4 / 2$ stochastic volatility model, using S \& P 500 index option data for pricing analysis.

\subsection{Research Status of SSE 50ETF Option Pricing}

In 2015, the emergence of China's first listed options on the Shanghai Stock Exchange 50 ETF options in the capital market has led to an explosive growth in domestic discussions and research on options pricing models.

Gu and Dong (2015) used the Shanghai and Shenzhen 300 stock index futures and the Shanghai 50ETF options as samples to analyze the correlation coefficients and deviations of volatility of dispersion trading, and then analyze the trading risks of the option pricing model. Yu and Chen (2016) used the theoretical framework of the B-S model to conduct an empirical analysis on the core parameters of the five SSE 50ETF options, including the underlying asset price, and made relevant recommendations for the supervisors from the perspective of contract design and risk control. At this stage, many scholars have conducted in-depth discussions on the pricing of SSE 50ETF options from multiple perspectives. Gong and Zhuang (2016) combined the asymmetric real variable high-order moment model characterizing the high-order moment characteristics of asset prices and the Levy process to describe the pure jump phenomenon of price changes, and constructed the Levy-NGARCHSK model; this model fully reflects the financial. The asset price path continues to be biased and leveraged. Under the assumption that the innovation term obeys the non-Gaussian Levy distribution, the author compares the accuracy and efficiency of the numerical integral Cosine method and the Monte Carlo simulation pricing method to the pricing of SSE 50ETF options. Fang, Zhang, and Qiao (2017) conducted an empirical comparative analysis of the performance of the B-S model and Monte Carlo simulation method on the pricing of SSE 50ETF options. The results show that the IGARCH model can better fit the volatility of the Shanghai Stock Exchange 50ETF than the traditional GARCH model. When the number of simulations is 1000 , the efficiency of the Monte Carlo method is consistently higher than that of the BSM model. The accuracy of other Monte Carlo models is also higher than the BSM model; both the BSM model and the Monte Carlo simulation method can accurately and effectively simulate the price of the SSE 50ETF option. Lei and $\mathrm{Wu}$ (2017) used the Tobit model to analyze the impact of the underlying asset liquidity on the SSE 50ETF option price and explained the validity of the option pricing; Hao and $\mathrm{Du}$ (2017) fused the GARCH model and the generalized hyperbolic distribution based on their respective advantages, a GARCH-GH option pricing model based on the SSE 50ETF was established. The 
results show that the pricing results of the GARCH-GH model are closer to the actual prices of the SSE 50ETF options than the BS model and the GARCHGaussian model. Wang and Yang (2016) used the high frequency data of the Shanghai 50ETF option to empirically analyze the pricing accuracy of a hybrid log-normal option pricing model with time-varying volatility, and found that the model was superior to the one with event volatility characteristics B-S improved model. Wu, Zhao, Li, \& Ma (2019) made in-depth research on option pricing under time-varying risk aversion, and concluded that TVRA-SV option pricing model has better data fitting effect than traditional CRA-SV option pricing model, and can more fully characterize the volatility of the SSE 50ETF return under the objective and risk-neutral measure. Wu, Li, \& Ma (2019) conducted an empirical test using a stochastic volatility model, showing that the random volatility model can obtain significantly more accurate and stable pricing results than the traditional constant volatility B-S model, both within and outside the sample.

Based on previous studies, this article uses the GARCH model to fit and predict the return volatility of the Shanghai 50ETF; the predicted volatility is used as the input value to substitute the fractal Brownian motion option pricing method, and the traditional and improved B-S option pricing method is used to estimate.

\section{The Establishment of Theoretical Methods and Models}

\subsection{Forecast Method of Yield Volatility}

When using the B-S model to price options, it is assumed that the volatility of asset prices is a constant value, which is not consistent with the actual financial market situation, and the volatility is time-varying. Therefore, scholars have proposed a series of stochastic volatility models to improve the B-S model, hoping to better characterize the characteristics of stochastic volatility. In summary, there are two main types of stochastic volatility models. One is a continuoustime stochastic volatility model (SV model), and the other is a discrete-time stochastic volatility model (GARCH model). In financial practice operations, transactions are performed discretely. The GARCH model describes discretetime economic situations and better reflects the actual situation of stock price operations in practice.

The GARCH model is an improvement of Bollerslev's autoregressive conditional heteroskedasticity (ARCH) model. It has been widely used in the financial field since its creation. If the random variable $y$ can be expressed as (1), $u$ is said to obey the $q$-order ARCH process.

$$
\begin{gathered}
y_{t}=\alpha_{0}+\alpha_{1} x_{t-1}+\alpha_{2} x_{t-2}+\cdots+\alpha_{m} x_{t-m}+u_{t} \\
\sigma_{t}^{2}=\beta_{0}+\beta_{1} u_{t-1}^{2}+\beta_{2} u_{t-2}^{2}+\cdots+\beta_{1 q} u_{t-q}^{2}
\end{gathered}
$$

Among them, since $\sigma_{t-2}$ is the predicted value of the variance of the previous period based on the previous information, it is called the conditional va- 
riance. It can be seen from the above model that the variance of the noise at the present moment is the regression of the square of the noise value of the finite term in the past. On the one hand, it can be seen that the fluctuation of the noise is affected by the previous period to produce memorability. The noise variance at the past moments becomes larger and larger, and vice versa. In practical terms, the overall level of volatility in the stock market in the previous period will lead to a higher level of volatility in the current period, which forms the aggregation and memory of the ARCH model. The probability density distribution is spiked and thick-tailed.

Adding the lag of the residual squared to the conditional variance of Equation (2) constitutes a GARCH model, as shown in Equation (3):

$$
\sigma_{t}^{2}=\beta_{0}+\beta_{1} u_{t-1}^{2}+\beta_{2} u_{t-2}^{2}+\cdots+\beta_{1 q} u_{t-q}^{2}+\chi_{1} \sigma_{t-1}^{2}+\cdots+\chi_{p} \sigma_{t-p}^{2}
$$

Among them $\beta_{1} u_{t-1}^{2}+\beta_{2} u_{t-2}^{2}+\cdots+\beta_{1 q} u_{t-q}^{2}$ is an ARCH term, $\chi_{1} \sigma_{t-1}^{2}+\cdots+\chi_{p} \sigma_{t-p}^{2}$ is a GARCH term. Constraints are:

$$
\beta_{0}>0 ; \beta_{1}, \cdots, \beta_{q} \geq 0 ; x_{1}, \cdots, x_{p} \geq 0 ; \sum_{i=1}^{q} \beta_{i}+\sum_{j=1}^{p} x_{j}<1
$$

The GARCH model believes that the variance of the error term in a certain period depends not only on the variance of the error term with respect to time, but also on the past error term itself. The model takes into account the lag value of the disturbance term and the lag value of the conditional variance of the disturbance term, which overcomes the ARCH model's inability to reflect the persistence of volatility, and is therefore widely used to describe the fluctuation of asset returns in financial markets. However, the GARCH model still does not solve the conditional heteroscedasticity in the early ARCH model, which depends on the size of the random perturbation without considering the positive and negative. This article does not discuss in depth.

A lot of empirical evidence shows that GARCH model has a good description of financial time series. Therefore, this paper uses the GARCH model to predict the volatility of SSE 50ETF returns. The prediction results are used as input values of the fractal Brownian motion model to price its options.

\subsection{Fractal Brownian Motion Option Pricing Method}

Geometric Brownian motion is an independent quantum process. It is a random process with continuous time parameters and continuous state space. However, the returns on financial assets are self-similar, thick-tailed, and long-memory. The assumption of random walk in financial markets is not valid. For example, some scholars found that the distribution of stock returns showed a "spike and thick tail". And the characteristics of the accumulation and persistence of volatility, Mandelbrot (1968) also confirmed the fact that there is a "spike and thick tail" in stock returns. Later many other scholars also revealed the fact that there is a long-range correlation in financial market returns. When studied the observations of financial time series, they found that there was a significant autocor- 
relation between these observations. Financial market data at different times show varying degrees of long memory and autocorrelation.

Therefore, it is no longer suitable to use geometric Brownian motion to characterize these features. Mandelbrot (1968) proposed fractal Brownian motion. Fractal Brownian motion has long-term correlation, self-similarity, and correlation between weights. These properties make it a very useful tool in mathematical finance. On this basis, Hu and Oksendal (2003) proposed the obedience process of asset price changes according to the proposed conditional expectations and proposed plans:

$$
\mathrm{d} S(t)=\mu(t) S(t) \mathrm{d} t+\sigma(t) S(t) \mathrm{d} B_{H}(T)
$$

Among them, $S(t)$ is a random sequence of financial asset prices, $0 \leq t \leq T$; $\mu(t)$ is the expected return rate of financial assets; $\sigma(t)$ is the annualized instant fluctuation rate of financial asset returns; $B_{H}(T)$ is Fractal Brownian motion with $H$ index, where $0<H<1$. When $H=0.5, B_{H}(T)$ is a geometric Brownian motion, which exhibits random walk characteristics, and the increment is independent; when $H>0.5, B_{H}(T)$ has a long-term dependence. There is a positive correlation between the increments; when $0<H<0.5$, $B_{H}(T)$ is anti-persistent, and the past increments are negatively correlated with the current increments.

At present, domestic scholars have carried out a large number of empirical studies on the Shanghai and Shenzhen stock markets, and found that China's capital market has significant fractal characteristics. For example, Zhuang and Huang (2003) studied the daily closing index of the Shanghai Composite Index and the Shenzhen Composite Index, and found that the Shanghai and Shenzhen stock market's return distribution is not a normal distribution, with fractal characteristics, and the index time series has a long-range correlation; $\mathrm{Xu}$ and $\mathrm{Xu}$ (2014) studied the long-term dependence of Shanghai index returns and pointed out that the option pricing method under the fractional Brownian motion model is more stable than the option pricing method under the standard Brownian motion.

Therefore, this paper uses the fractal Brownian motion to characterize the benefits of the Shanghai 50 ETF. We borrow from Ciprian Necula's method, assuming that the market is complete and there is no arbitrage, and apply Wick points to introduce the B-S European option pricing formula under the fractal Brownian motion environment:

$$
\begin{gathered}
C(S(t), t, K)=S(t) N\left(d_{1}\right)-K \mathrm{e}^{-r(T-t)} N\left(d_{2}\right) \\
\text { Among them, } d_{1}=\frac{\ln \left\{\frac{S(t)}{K}\right\}+r(T-t)+0.5 \sigma^{2}\left(T^{2 H}-t^{2 H}\right)}{\sigma \sqrt{T^{2 H}-t^{2 H}}} \\
d_{2}=\frac{\ln \left\{\frac{S(t)}{K}\right\}+r(T-t)-0.5 \sigma^{2}\left(T^{2 H}-t^{2 H}\right)}{\sigma \sqrt{T^{2 H}-t^{2 H}}}, N() \text { is the distribution function of }
\end{gathered}
$$

the standard normal distribution. 


\section{Empirical Steps}

\subsection{Sample Selection and Pretreatment}

This article uses the daily closing price of the Shanghai Stock Exchange 50ETF as the research object, and selects the 10 groups of daily closing prices of the 50ETF for the September 3500 code (10001218.SH) contract from January 25, 2018 to February 7, 2018 as the actual options Price, the bank's one-year deposit benchmark interest rate is selected as the risk-free interest rate: $r=1.50 \%$, the maturity date is September 26, 2018, and the exercise price is $k=3.5000$ (reason for selection: expired, subscription option). Forecasted Volatility This article selects the daily closing price of the Shanghai Stock Exchange 50ETF from January 4, 2016 to January 24, 2018 as the research object, for a total of 507 trading days.

When estimating the Hurst index $H$, first take the logarithmic return on the closing price of these 507 trading days. The processing formula is:

$R_{t}=100\left(\ln P_{t}-\ln P_{t-1}\right)$. This is because transforming the raw data into logarithmic returns will eliminate some of the unstable factors that may exist in the raw data. At the same time, before re-scaling the range (R/S) analysis of these 507 data, they will first be logarithmic. The return rate, $R_{b}$ is tested for normality. Use Eviews to perform a normal test on the series of logarithmic returns. The test results are shown in Table 1. After the text edit has been completed, the paper is ready for the template. Duplicate the template file by using the Save As command, and use the naming convention prescribed by your journal for the name of your paper. In this newly created file, highlight all of the contents and import your prepared text file. You are now ready to style your paper.

It can be seen from Table 1 that the logarithmic return sequence of the 50ETF closing price is left-biased, and the kurtosis is greater than 3 , indicating that it has the characteristics of "peak and thick tail". Because the JB statistic is larger than its critical value and the probability is small, this logarithmic rate of return

Table 1. Normality test of 50ETF logarithmic return series.

\begin{tabular}{cc}
\hline Statistical index & Statistics \\
Mean & 0.0537 \\
Median & 0.0454 \\
Max & 3.8811 \\
Minimum & -6.2325 \\
Standard deviation & 1.0253 \\
Skewness & -1.1859 \\
Kurtosis & 11.3662 \\
Jarque-Bera Statistics & 1597.4620 \\
$P$-value & 0.0000 \\
Number & 507.0000 \\
\hline
\end{tabular}


sequence rejects the null hypothesis, that is, it does not obey the normal distribution hypothesis. Therefore, using the B-S model to price the options with the closing price of 50ETF as the underlying asset will inevitably cause deviations, and it is more reasonable to use fractal Brownian motion to describe price fluctuations.

\subsection{Stationarity Test}

A test of the SSE 50ETF return rate stability shows that the ADF stationarity test statistic value of the return series is -25.70252 , which is less than the critical value at the significance level of $1 \%-3.444346$, and less than the significance level of $5 \%$ and the critical values of -2.867032 and -2.569757 at $10 \%$ show that the yield series are stationary time series (Table 2).

Table 2. The results of stationarity test.

\begin{tabular}{|c|c|c|c|c|}
\hline \multicolumn{5}{|c|}{ Null Hypothesis: R has a unit root } \\
\hline \multicolumn{5}{|c|}{ Exogenous: Constant } \\
\hline \multicolumn{5}{|c|}{ Lag Length: 0 (Automatic-based on SIC, maxlag = 18) } \\
\hline & & & t-Statistic & Prob. $^{*}$ \\
\hline Augmente & xey-Fuller tes & & -25.70252 & 0.0000 \\
\hline & & & -3.443046 & \\
\hline \multirow[t]{2}{*}{ Test critical values: } & & & -2.867032 & \\
\hline & & & -2.569757 & \\
\hline \multicolumn{5}{|c|}{${ }^{\star}$ MacKinnon (1996) one-sided p-values. } \\
\hline \multicolumn{5}{|c|}{ Augmented Dickey-Fuller Test Equation } \\
\hline \multicolumn{5}{|c|}{ Dependent Variable: D (R) } \\
\hline \multicolumn{5}{|l|}{ Method: Least Squares } \\
\hline \multicolumn{5}{|c|}{ Sample (adjusted): 1/05/2016 1/24/2018 } \\
\hline \multicolumn{5}{|c|}{ Included observations: 506 after adjustments } \\
\hline Variable & Coefficient & Std. Error & t-Statistic & Prob. \\
\hline $\mathrm{R}(-1)$ & -1.100279 & 0.042808 & -25.70252 & 0.0000 \\
\hline $\mathrm{C}$ & 0.070805 & 0.043952 & 1.610968 & 0.1078 \\
\hline R-squared & 0.567241 & \multicolumn{2}{|c|}{ Mean dependent var } & 0.011564 \\
\hline Adjusted R-squared & 0.566382 & \multicolumn{2}{|c|}{ S.D. dependent var } & 1.499345 \\
\hline S.E. of regression & 0.987314 & \multicolumn{2}{|c|}{ Akaike info. criterion } & 2.816288 \\
\hline Sum squared resid & 491.2939 & \multicolumn{2}{|c|}{ Schwarz criterion } & 2.832994 \\
\hline Log likelihood & -710.5209 & \multicolumn{2}{|c|}{ Hannan-Quinn criter. } & 2.82284 \\
\hline F-statistic & 660.6194 & \multicolumn{2}{|c|}{ Durbin-Watson stat } & 1.991526 \\
\hline Prob. (F-statistic) & 0.0000 & & & \\
\hline
\end{tabular}




\subsection{Autocorrelation and Partial Autocorrelation Test}

On the basis of the stability test, the autocorrelation and partial autocorrelation of the returns are further tested. Calculate the 36-order lag term correlation coefficient and partial autocorrelation coefficient of the yield time series residual and squared residual, respectively, and find that both of them have autocorrelation and partial autocorrelation. Combined with the AIC principle, AR (2) has the best Fitting results (Table 3 and Figure 1).

In order to further test whether the yield sequence has $\mathrm{ARCH}$ effect, the ARCH-LM test is performed on the residual sequence after AR (2) fitting. The results show that the $\mathrm{P}$ values are all 0 , and the null hypothesis that the sequence has no ARCH effect is rejected. As shown in the table; the ARCH effect of the residual sequence is obvious, that is, the residual of the AR (2) model has autoregressive conditional heteroscedasticity (Table 4).

\begin{tabular}{|c|c|c|c|c|c|c|}
\hline Autocorrelation & Partial Correlation & & $A C$ & PAC & Q-Stat & Prob \\
\hline ון ו 1 & $1 \mid 11$ & 1 & 0.019 & 0.019 & 0.1782 & 0.673 \\
\hline $1 \square$ & । & 2 & 0.206 & 0.206 & 21.905 & 0.000 \\
\hline 15 & 17 & 3 & 0.127 & 0.125 & 30.122 & 0.000 \\
\hline 叶 & 11 & 4 & 0.158 & 0.122 & 42.932 & 0.000 \\
\hline 1 & 1 & 5 & 0.049 & 0.002 & 44.144 & 0.000 \\
\hline $1 \square$ & 17 & 6 & 0.169 & 0.109 & 58.871 & 0.000 \\
\hline $1 \square$ & 11 & 7 & 0.148 & 0.120 & 70.094 & 0.000 \\
\hline 1) & ימן & 8 & 0.094 & 0.033 & 74.687 & 0.000 \\
\hline ו & 1 & 9 & 0.029 & -0.054 & 75.109 & 0.000 \\
\hline 1曰 & 19 & 10 & 0.136 & 0.058 & 84.688 & 0.000 \\
\hline
\end{tabular}

Figure 1. Residual autocorrelation and partial autocorrelation of SSE 50ETF return time series.

Table 3. The results of Autocorrelation and partial autocorrelation test.

\begin{tabular}{ccccc}
\hline Variable & Coefficient & Std. Error & t-Statistic & Prob. \\
\hline AR (1) & -0.094988 & 0.04494 & -2.11364 & 0.035 \\
AR (2) & 0.082117 & 0.0297 & 2.764861 & 0.0059 \\
SIGMASQ & 1.034962 & 0.029898 & 34.61627 & 0.0000 \\
R-squared & 0.013561 & Mean dependent var & 0.053676 \\
Adjusted R-squared & 0.009646 & S.D. dependent var & 1.025311 \\
S.E. of regression & 1.020354 & Akaike info criterion & 2.884124 \\
Sum squared resid & 524.7259 & Schwarz criterion & 2.909145 \\
Log likelihood & -728.1255 & Hannan-Quinn criter. & 2.893937 \\
Durbin-Watson stat & 1.93839 & &
\end{tabular}

Table 4. The results of heteroskedasticity test.

\begin{tabular}{cccc}
\hline \multicolumn{4}{c}{ Heteroskedasticity Test: } \\
\hline FRCH \\
\hline Obstatistic & 33.32055 & Prob. F $(3,500)$ & 0.0000 \\
& 83.97316 & Prob. Chi-Square (3) & 0.0000 \\
\hline
\end{tabular}




\subsection{Build AR (2)-GARCH $(1,1)$ Model}

In view of the above-mentioned sample data test, the return rate is a stationary series and there is a test result of the ARCH effect, the time series of the return rate meets the conditions for the construction of the GARCH model. This article establishes an AR (2)-GARCH $(1,1)$ model to characterize the volatility of the rate of return. The specific formula for model parameter estimation is as follows:

$$
\begin{gathered}
r_{t}=0.090167+0.021066 r_{t-1}+0.004300 r_{t-2}+\varepsilon_{t} \\
\sigma_{t}^{2}=0.024159+0.023492 \varepsilon_{t-1}^{2}+0.931664 \sigma_{t-1}^{2}
\end{gathered}
$$

In the parameter estimation model,

$$
\beta_{0}=0.024159>0, \beta_{1}=0.931664>0, \chi_{1}=0.023492>0
$$

And meet the constraints of GARCH model construction, that is,

$$
\beta_{1}+\chi_{1}=0.931664+0.023492=0.955156<1
$$

The autocorrelation and partial autocorrelation tests were performed on the residuals and residual squares after simulation by the AR (2)-GARCH $(1,1)$ model, and it was found that there was no autocorrelation and partial autocorrelation. This paper performs an ARCH test on the simulated residuals and finds that the $P$-value in the ARCH test results of the residual sequence simulated by AR (2)-GARCH $(1,1)$ is not 0 , indicating that the simulated residual sequence does not exist in ARCH effect.

In summary, after processing by the $\operatorname{GARCH}(1,1)$ model, various information of the yield sequence is well described. Therefore, the GARCH model con-

\begin{tabular}{|c|c|c|c|c|}
\hline \multicolumn{5}{|c|}{ Heteroskedasticity Test: ARCH } \\
\hline F-statistic & 0.110885 & Prob. F $(3,498)$ & \multicolumn{2}{|c|}{0.9537} \\
\hline Obs * R-squared & 0.335102 & Prob. Chi-Square (3) & \multicolumn{2}{|c|}{0.9533} \\
\hline Variable & Coefficient & Std. Error & z-Statistic & Prob. \\
\hline $\mathrm{C}$ & 0.090167 & 0.038666 & 2.331941 & 0.0197 \\
\hline $\operatorname{AR}(1)$ & 0.021066 & 0.046412 & 0.453901 & 0.6499 \\
\hline \multirow[t]{2}{*}{$\operatorname{AR}(2)$} & 0.0043 & 0.047279 & 0.090947 & 0.9275 \\
\hline & \multicolumn{2}{|c|}{ Variance Equation } & & \\
\hline $\mathrm{C}$ & 0.024159 & 0.004306 & 5.610171 & 0.0000 \\
\hline $\operatorname{RESID}(-1)^{\wedge} 2$ & 0.023492 & 0.009911 & 2.370151 & 0.0178 \\
\hline GARCH (-1) & 0.931664 & 0.009624 & 96.81061 & 0.0000 \\
\hline R-squared & -0.004682 & \multicolumn{2}{|c|}{ Mean dependent var } & 0.064841 \\
\hline Adjusted R-squared & -0.008685 & \multicolumn{2}{|c|}{ S.D. dependent var } & 0.992593 \\
\hline S.E. of regression & 0.996894 & \multicolumn{2}{|c|}{ Akaike info criterion } & 2.494602 \\
\hline Sum squared resid & 498.8862 & \multicolumn{2}{|c|}{ Schwarz criterion } & 2.544795 \\
\hline Log likelihood & -623.887 & \multicolumn{2}{|c|}{ Hannan-Quinn criter. } & 2.514289 \\
\hline Durbin-Watson stat & 2.249845 & & & \\
\hline
\end{tabular}
structed in this paper is reasonable to characterize the volatility of returns (Table $5)$.

Table 5. The results of heteroskedasticity test and the GARCH model. 


\subsection{Forecast of Volatility}

Based on the estimated AR (2)-GARCH $(1,1)$ model, this article uses January 24, 2018 as the base date to predict the daily volatility of $r^{2}$ s future 10-day yield and then calculate the future of $r / 100$ The 10-day daily volatility is shown in Table 6. Due to the fractal Brownian motion, the volatility used in the formula for price changes is annualized volatility. Therefore, this article converts the daily volatility in the next 10 days into annual volatility, and the number of trading days in 2018 is 243 days (Figure 2).

Annualized volatility $=$ Daily volatility $\times \sqrt{\text { Days traded per year }}$

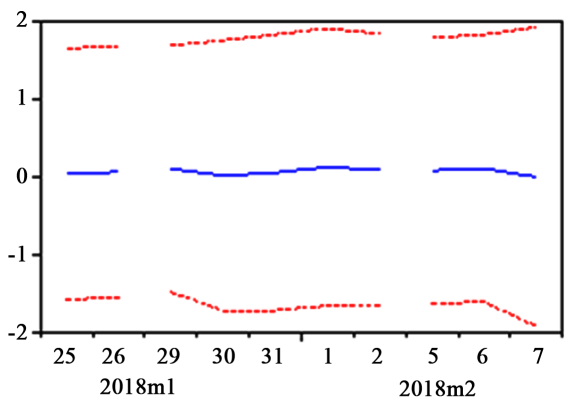

Forecast: RF

Actual: R

Forecast sample: 1/25/2018 2/07/2018

ncluded observations: 10

Root Mean Squared Error 1.499953

Mean Absolute Error $\quad 1.270982$

Mean Abs. Percent Error $\quad 95.27030$

Theil Inequality Coefficient 0.958554

Bias Proportion $\quad 0.133510$

Variance Proportion $\quad 0.832867$

Covariance Proportion $\quad 0.033623$

Theil U2 Coefficient $\quad 0.841787$

Symmetric MAPE $\quad 178.0954$

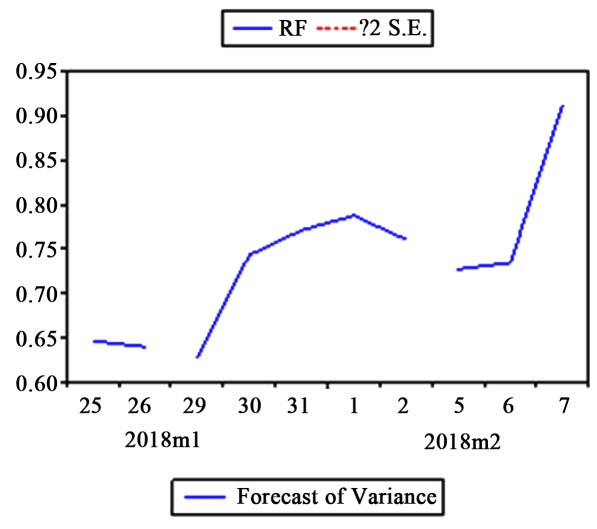

Figure 2. The trend of forecasted of variance on SSE 50ETF.

Table 6. Forecasted SSE 50ETF yield volatility data for the next 10 days.

\begin{tabular}{ccc}
\hline Time & $\begin{array}{c}\mathrm{r} / 100 \text { Volatility } \\
\text { in the next 10 days }\end{array}$ & $\begin{array}{c}\mathrm{r} / 100 \text { Annualized volatility } \\
\text { in the next } 10 \text { days }\end{array}$ \\
\hline $2018 / 1 / 25$ & 0.008086555 & 0.222338132 \\
$2018 / 1 / 26$ & 0.008036847 & 0.220971433 \\
$2018 / 1 / 29$ & 0.007945389 & 0.218456817 \\
$2018 / 1 / 30$ & 0.00867912 & 0.238630578 \\
$2018 / 1 / 31$ & 0.008865426 & 0.243753020 \\
$2018 / 2 / 1$ & 0.008922636 & 0.245325997 \\
$2018 / 2 / 2$ & 0.008750858 & 0.240603001 \\
$2018 / 2 / 5$ & 0.008542176 & 0.234865325 \\
$2018 / 2 / 6$ & 0.008593186 & 0.236267855 \\
$2018 / 2 / 7$ & 0.009626747 & 0.264685392
\end{tabular}




\subsection{Calculation of Hurst Index}

There are seven main methods for calculating Hurst index: Aggregated Variance method, R/S method, Period ogram method, Absolute Value method, residual Variance of residuals, Abry-Veitch method, Whittle estimator.

This paper uses the R/S analysis method and matlab to calculate the Hurst index $H=0.6334$ for a total of 507 data from January 4, 2016 to January 24, 2018.

The specific method is: segment the yield sequence and divide it into A (taken the integer part of $N / n)$ consecutive subsequences of length $n(\geq 2)$. In order to estimate the Hurst exponent $H$, the length of the subsequence $n$ is increased to the next larger factor until $n=N / 2$, so as to obtain the $\{(\mathrm{R} / \mathrm{S}) n\}$ sequence, which in this paper has reached the length of the yield sequence length. So far, the rescaled range difference values can be obtained in this way. The two sets of rescaled range differences $n,(\mathrm{R} / \mathrm{S}) n$ take natural logarithms, establish a regression equation, and calculate the slope as the required Hurst index $H$.

The Hurst index $H$ calculated above is greater than 0.5 , which indicates that the future trend of the SSE 50ETF is positively correlated with the past trend, that is, it is persistent and continuous, that is, long-term memory. This also shows that the market is not an effective market, but a fractal market. The volatility of earnings is persistent, long-term memory and non-linear, and current events will affect the future market for a long time. Therefore, when making decisions on the corresponding risk investment management and asset pricing, it should be based on the fractal market hypothesis and related methods.

\section{Empirical Results and Analysis}

\subsection{Empirical Results}

This article selects 10 groups of daily closing prices of 50ETF for the September 3500 code (10001218.SH) contract from January 25, 2018 to February 7, 2018 as the research object. Subsequently, the modified BS option pricing method combined with the GARCH model and the standard BS option pricing method under the fractal Brownian motion proposed in this paper were used to simulate the pricing of the SSE 50ETF to purchase September 3500 options, and then the two pricing results were respectively compared with the actual option transaction price Perform comparative analysis.

When using the standard BS option pricing method, the following formula is used to calculate the daily historical volatility of the SSE 50ETF return from January 4, 2016 to January 24, 2018, and the annualized volatility calculation formula is used to obtain this period. The annualized historical volatility is 0.281629 .

$$
s=\sqrt{\frac{1}{n-1} \sum_{i=1}^{n}\left(R_{i}-\bar{R}\right)}
$$

When using the improved B-S option pricing method combined with GARCH model under fractal Brownian motion, the option pricing formula uses: 


$$
\begin{aligned}
& C(S(t), t, K)=S(t) N\left(d_{1}\right)-K \mathrm{e}^{-r(T-t)} N\left(d_{2}\right) \\
& d_{1}=\frac{\ln \left\{\frac{S(t)}{K}\right\}+r(T-t)+0.5 \sigma^{2}\left(T^{2 H}-t^{2 H}\right)}{\sigma \sqrt{T^{2 H}-t^{2 H}}}, \\
& d_{2}=\frac{\ln \left\{\frac{S(t)}{K}\right\}+r(T-t)-0.5 \sigma^{2}\left(T^{2 H}-t^{2 H}\right)}{\sigma \sqrt{T^{2 H}-t^{2 H}}},
\end{aligned}
$$

$N(\cdot)$ is the distribution function of the standard normal distribution, and the volatility uses the sequence values predicted by the GARCH model.

The calculation results are shown in Table 7.

Comparing the calculation results of standard B-S and improved B-S pricing, the results calculated by the improved B-S model are closer to the actual price of options; their average absolute error rate is also smaller.

Based on the calculation results, the fitted images of theoretical prices and market prices in different models are drawn. Figure 3 can more intuitively show that the improved B-S model is better than the standard B-S model.

\subsection{Model Analysis}

Use the actual market price and the theoretical root mean square error (RMSE) to measure the pros and cons of the model.

$$
\mathrm{RMSE}=\sqrt{\left[\sum_{i=1}^{n}\left(\frac{P_{\text {actual }}^{i}-P_{\text {Theoretical }}^{i}}{K / S}\right)^{2}\right] / n}
$$

where $S$ is the target market price and $K$ is the execution price (Table 8).

Table 7. Comparison of standard B-S and improved B-S pricing results.

\begin{tabular}{cccccc}
\hline & \multirow{2}{*}{$\begin{array}{c}\text { Actual } \\
\text { Date }\end{array}$} & \multicolumn{2}{c}{ Standard B-S } & \multicolumn{2}{c}{ Improved B-S } \\
\cline { 3 - 6 } & price & Option price & Error rate & Option price & Error rate \\
\hline $2018 / 1 / 25$ & 0.12 & 0.169186299 & $40.99 \%$ & 0.128781871 & $7.32 \%$ \\
$2018 / 1 / 26$ & 0.1229 & 0.178211382 & $45.01 \%$ & 0.134623817 & $9.54 \%$ \\
$2018 / 1 / 29$ & 0.0927 & 0.157544229 & $69.95 \%$ & 0.113674813 & $22.63 \%$ \\
$2018 / 1 / 30$ & 0.0805 & 0.144597953 & $79.62 \%$ & 0.12113983 & $50.48 \%$ \\
$2018 / 1 / 31$ & 0.095 & 0.158903813 & $67.27 \%$ & 0.139329606 & $46.66 \%$ \\
$2018 / 2 / 1$ & 0.1008 & 0.167546765 & $66.22 \%$ & 0.149361631 & $48.18 \%$ \\
$2018 / 2 / 2$ & 0.1085 & 0.172595829 & $59.07 \%$ & 0.14866564 & $37.02 \%$ \\
$2018 / 2 / 5$ & 0.1233 & 0.187206804 & $51.83 \%$ & 0.155827127 & $26.38 \%$ \\
$2018 / 2 / 6$ & 0.1128 & 0.161228857 & $42.93 \%$ & 0.133210184 & $18.09 \%$ \\
$2018 / 2 / 7$ & 0.0875 & 0.132126905 & $51.00 \%$ & 0.132608954 & $51.55 \%$ \\
\hline Mean absolute error rate & - & - & $57.39 \%$ & - & $31.79 \%$ \\
\hline
\end{tabular}




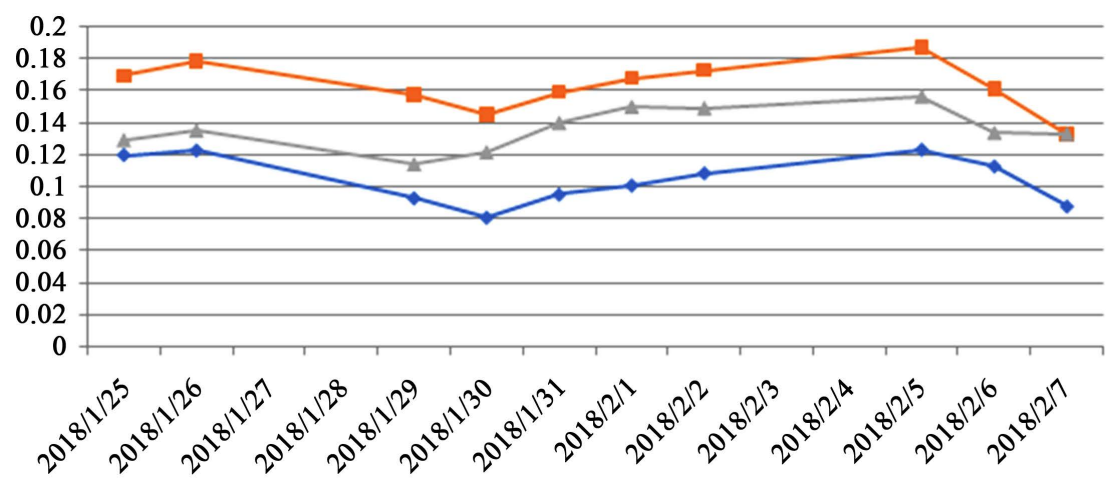

Figure 3. Theoretical price based on Standard B-S model and improved B-S model and market price.

Table 8. Precision comparison between standard B-S and improved B-S.

\begin{tabular}{cccc}
\hline Model & Mean absolute error rate & RMSE & Improved accuracy over standard B-S \\
\hline Normal B-S & $57.39 \%$ & 0.0527 & - \\
Improved B-S & $31.79 \%$ & 0.0304 & $42.26 \%$ \\
\hline
\end{tabular}

According to the calculation results, the average absolute error rate and RMSE of the improved B-S model are smaller than the results of the standard B-S model. Compared with the standard B-S, the improved accuracy of the improved B-S is calculated as follows:

$$
1-\frac{\text { RMSE of improved B-S }}{\text { RMSE of normal B-S }}=1-\frac{0.0304}{0.0527}=42.26 \%
$$

It can be seen that the improved B-S model improves the accuracy of $42.26 \%$ compared to the standard B-S.

\section{Conclusion}

This article proposes a Shanghai Stock 50ETF option pricing method based on the GARCH model. The empirical results show that the SSE 50ETF exhibits spikes and thick tails, conditional heteroscedasticity, and fractal phenomena. Through the stationary test, it is found that the Shanghai 50ETF return series is a stationary time series. According to the autocorrelation and partial autocorrelation tests, it is found that both of them have autocorrelation and partial autocorrelation and the ARCH effect of the residual series is obvious. Therefore, the AR (2)-GARCH $(1,1)$ model can well describe the fluctuation of the return rate. The final empirical results show that the prediction accuracy of the Shanghai Securities 50ETF option pricing method based on the GARCH fractal Brownian motion model is significantly higher than the standard B-S option pricing method.

\section{Conflicts of Interest}

The author declares no conflicts of interest regarding the publication of this paper. 


\section{References}

Andrés-Sánchez, J. D. (2017). An Empirical Assestment of Fuzzy Black and Scholes Pricing Option Model in Spanish Stock Option Market. Journal of Intelligent \& Fuzzy Systems, 33, 2509-2521. https://doi.org/10.3233/JIFS-17719

Bailey, W., \& Stulz, R. M. (1989). The Pricing of Stock Index Options in a General Equilibrium Model. Journal of Financial \& Quantitative Analysis, 24, 1-12. https://doi.org/10.2307/2330744

Bollerslev, T. (1986). Generalized Autoregressive Conditional Heteroscedasticity. Journal of Econometrics, 31, 307-327. https://doi.org/10.1016/0304-4076(86)90063-1

Cheng, Z. Y., Guo, J. J., \& Zhang, Y. F. (2018). Pricing European Options for Dividend Payment under Subfractional Brownian Motion. Applied Probability Statistics, 34, $37-48$.

Corrado, C., \& Su, T. (1998). An Empirical Test of the Hull-White Option Pricing Model. Journal of Futures Markets, 18, 363-378. https://doi.org/10.1002/(SICI)1096-9934(199806)18:4<363::AID-FUT1>3.0.CO;2-K

Fang, Y., Zhang, Y. X., \& Qiao, M. Z. (2017). Study on the Pricing Effectiveness of Shanghai 50ETF Options: Based on B-S-M Model and Monte Carlo Simulation. Operations Research and Management, 26, 157-166.

Gong, X. L., \& Zhuang, X. T. (2016). Option Pricing Based on High-Order Moment Wave Model of Levy Process. Systems Engineering, 34, 22-28.

Gu, G. D., \& Dong, H. Y. (2015). An Empirical Study and Discussion on Transaction of Disparity. Economics and Management, 29, 74-78.

Hao, M., \& Du, Z. P. (2017). Research on Pricing of Shanghai Stock Exchange 50ETF Options Based on GARCH-GH Model. Mathematics in Practice and People, 47, 289-296.

Hu, Y., \& Oksendal, B. (2003). Franctional White Noise Calculus and Applications to Finance. Infinite Dimensional Analysis, Quantum Probability and Related Topics, 6, 1-32. https://doi.org/10.1142/S0219025703001110

Huang, H. N., \& Zhong, W. (2007). Volatility Prediction and Evaluation of GARCH Models. China Management Science, 15, 13-19.

Ji, Q. (2015). Research on Pricing of SSE 50ETF Options. Business Manager, 29, 23-24.

Kim, N., \& Lee, J. (2013). No-Arbitrage Implied Volatility Functions: Empirical Evidence from KOSPI 200 Index Options. Journal of Empirical Finance, 21, 36-53. https://doi.org/10.1016/j.jempfin.2012.12.007

Lei, S. D., \& Wu, W. F. (2017). Research on the Validity of SSE 50ETF Option Price-Based on the Theory of Option Parity. Price Theory and Practice, No. 4, 116-119.

Levy, H., \& Byun, Y. H. (1987). An Empirical Test of the Black-Scholes Option Pricing Model and the Implied Variance: A Confidence Interval Approach. Journal of Accounting Auditing \& Finance, 2, 80-91. https://doi.org/10.1177/0148558X8700200403

Liao, W., Hu, T. H., \& Song, M. M. (2013). Empirical Research on Option Pricing Model Based on Fractional Brownian Motion and KOSPI200 Index Options. Financial Economy, 22, 135-137.

Liu, W. Q., Wei, C. M., \& Bu, X. Z. (2018). Pricing of European Barrier Options under Mixed Fractional Brownian Motion. Economic Mathematics, 35, 16-20.

Mandelbrot, B., \& van Ness, J. (1968). Fractional Brownian Motions, Fractional Noises and Applications. SIAM Review, 10, 422-437. https://doi.org/10.1137/1010093 
Oliver, X., \& Li, W. (2015). Hedging Jump Risk, Expected Returns and Risk Premia in Jump-Diffusion Economies. Quantitative Finance, 15, 873-888. https://doi.org/10.1080/14697688.2014.946439

Qin, X. Z., Lin, X. W., \& Wang, W. H. (2019). Research on Fuzzy Pricing of European Options Based on Long Memory Characteristics. Systems Engineering Theory and Practice, 39, 3073-3083.

Saurabha, R., \& Tiwari, M. (2007). Empirical Study of the Effect of Including Skewness and Kurtosis in Black Scholes Option Pricing Formula on S\&P CNX Nifty Index Options. SSRN Electronic Journal, 29, 63-77. https://doi.org/10.2139/ssrn.1075583

Song, B., Lin, Z. F., Liu, L. L. et al. (2013). Pricing Model of Convertible Bonds Based on Game Options and Empirical Research. Journal of Systems Management, 22, 758-767.

Wang, B., Zhu, S. W., Deng, Y. D., \& Liao, X. (2019). Option Pricing under the 4/2 Stochastic Volatility Model. Journal of Systems Management, 28, 1152.

Wang, P., \& Yang, X. L. (2016). Pricing of 50ETF Options Based on Time-Varying Volatility and Mixed Log-Normal Distribution. Management Science, 29, 149-160.

Wu, X. Y., Li, X. D., \& Ma, C. Q. (2019). Research on Shanghai Stock 50ETF Option Pricing Based on Stochastic Volatility Model. Mathematical Statistics and Management, 38, 115-131.

Wu, X. Y., Zhao, K., Li, X. D., \& Ma, C. Q. (2019). Option Pricing under Time-Varying Risk Aversion: An Empirical Study Based on Shanghai 50ETF Options. China Management Science, 27, 11-22.

Xu, L., \& Xu, T. (2014). Long Dependence Analysis of Shanghai Stock Index Returns and European Option Pricing. Journal of East China Normal University (Natural Science), $5,14-22$.

Yu, C. F., \& Chen, T. T. (2016). An Empirical Study on the Pricing of Shanghai 50ETF Options Based on B-S Model. Financial Theory and Teaching, 2, 7-11.

Yung, H. H. M., \& Zhang, H. (2003). An Empirical Investigation of the GARCH Option Pricing Model: Hedging Performance. Journal of Futures Markets, 23, 1191-1207. https://doi.org/10.1002/fut.10109

Zheng, Z. L., \& Huang, Y. Z. (2010). GARCH Model and Implied Volatility. Quantitative and Technical Economics Research, 1, 141-143.

Zhuang, X. T., \& Huang, X. Y. (2003). Research on Optimal Investment of Real Options under Asymmetric Information. Journal of Management Sciences in China, 6, 28-33. 